\title{
O sistema de comunicação da ciência e o taylorismo acadêmico: questionamentos e alternativas
}

\author{
IVAN DOMINGUES ${ }^{I}$
}

\begin{abstract}
"Este livro é destinado aos leitores calmos, aos homens que não foram ainda arrastados pela pressa vertiginosa de nossa época precipitada e que não experimentaram um prazer idólatra de deixar-se esmagar por suas rodas, portanto, a bem poucos homens!”
\end{abstract}

(Nietzsche, Segundo Prefácio, 2003, p.46)

\section{Introdução}

$\int$

STE ARTIGO sintetiza e dá remate a uma série de elocuções que nos últimos tempos protagonizamos em diferentes campos dos chamados "estudos sociais da ciência e da técnica" (science and technology studies), focalizando desta feita o tema do taylorismo acadêmico, seu modus operandi, seu aparato institucional, suas ferramentas e suas consequências.

Duas são as ideias axiais, as quais aparecem no título e requerem uma justificativa inicial, cujo alcance e significado só serão evidenciados em sua inteireza ao fim do estudo.

A primeira diz respeito ao sistema de comunicação da ciência, que distinguimos da divulgação da ciência e de sua irmã gêmea, a popularização. Embora tenha o mesmo componente de mídias e linguagem, mas seja distinta da divulgação/popularização pelo conteúdo e escopo, o sistema de comunicação terá por foco não a difusão da ciência junto ao público leigo, porém a veiculação da produção e dos resultados da ciência junto aos pares, abarcando as sessões das academias, as cátedras das universidades, os ciclos de conferências, os livros, as revistas científicas, os artigos, o sistema de revisão por pares . E como tal abarca os indexadores, os índices de impacto etc.

A segunda considera o taylorismo acadêmico como um mal que atinge a academia e o sistema de comunicação da ciência, cuja pertinência e delimitação exigirão a comparação com outros males, além da confrontação com outros conceitos e vocábulos. Antes de tudo, a comparação com o tarefismo, em que 
vemos o mal maior, além de mais corrente e banalizado, resultante de uma estrutura confusa e irracional, caracterizada pela pletora de tarefas, solicitações e procedimentos que deixam a universidade pública brasileira esgarçada e uma grande parcela dos professores exaurida. Diferentemente, o taylorismo é um mal que atinge, como em outras partes do mundo, os segmentos da universidade ligados à pós-graduação e à pesquisa, onde as coações e os incentivos à produção de conhecimento novo vão juntos com as formas de auditagem e controle da produção, que são os expedientes administrativos comumente utilizados nas fábricas e nas grandes corporações , como em seus congêneres econômicos. O outro nome para "taylorismo" bem poderia ser "produtivismo", com a vantagem da popularidade e ampla aceitação. Todavia, para os nossos propósitos, importava ressaltar o viés administrativo da produção acadêmica, associado ao sistema de incentivos e coerções, que vão junto com as recompensas e as punições, permeáveis às coerções dos governos, das agências de fomento, da administração central das universidades, levando à estandardização dos processos e à explosão das publicações. Daí a preferência por taylorização e seu par taylorismo. ${ }^{1}$

No Brasil, embora o taylorismo seja real e já cause seus conhecidos estragos, ele nem mesmo aparece como problema para a maioria dos colegas, tão legitimado ele está nos meios acadêmicos, deixando todo mundo feliz justamente porque vivos e "produtivos", como se fosse a coisa mais importante do mundo lançar uma linha a mais no Lattes. Contudo, há mais de um motivo para questionarmos isso, conforme veremos.

\section{O sistema de comunicação da ciência e seu aparato acadêmico-institucional}

Antes de mais nada, é preciso delimitar o recorte e circunscrever o conceito. De saída, não pretendemos analisar o papel epistêmico-pedagógico das academias e das universidades, nem mesmo os processos sociológicos e institucionais da produção científica, focalizando as agências de fomento, os órgãos de governo, e a Ciência e Tecnologia (C\&T) como matérias de políticas públicas. Tampouco nos concentraremos no papel dos aparatos de divulgação científica livros, revistas, museus, observatórios etc. -, com seu importante legado na educação e na cultura científicas, em um tempo como o nosso no qual a fragmentação e a especialização chegaram a níveis inimagináveis, semeando o hermetismo e a ignorância. Na sequência, vamos nos restringir ao sistema de comunicação da ciência e seu aparato (livros, artigos, anais de congresso, formas de seleção e triagem, indexadores etc.) criado pelas universidades, academias e corporações afins com a missão de dar vazão à produção dos cientistas e pesquisadores.

Ora, quem fala em hermetismo e em comunicação fala em linguagem em sua diversidade e profusão de manifestações: elocução oral, manuscritos inacabados, textos escritos para publicação, simbolismos e grafismos, números e medidas diversas. Não é de outra coisa que fala a Royal Society of London, quando, em 1667, sete anos depois de sua fundação, diz que "precisa de um 
modo de falar nu, natural, de significados claros, e uma preferência para a linguagem dos artesãos e dos comerciantes" (Sprat apud Castelfranchi, 2008, p.4). Pouco importa se o que aconteceu depois, patrocinado pela própria Sociedade, foi o hermetismo dos jargões técnicos e a linguagem cifrada dos números, com as fórmulas matemáticas impenetráveis ao leigo. Hermética ou não, o certo é que a ciência nova nascente travou um duro combate contra a velha linguagem rebuscada e pedante da escolástica medieval, com suas sutilezas teológico-filosóficas em latim, e abriu o caminho para as publicações e as discussões nas línguas nacionais, como o inglês com seus barbarismos, malgrado Shakespeare. Não obstante o que prevalecerá depois será uma scientia nova mais e mais hermética, com sua babel de jargões e linguagens especializadas, verdadeiros dialetos, o sistema de comunicação é a instituição fundamental da ciência moderna, abarcando os livros, as revistas, as sessões públicas das academias e as discussões privadas no interior delas (Ziman apud Castelfranchi, 2008, p.192). Donde a dualidade característica do sistema, fechada ao grande público e exclusiva de iniciados, e ao mesmo tempo aberta e franqueada ao público laico. Então, desde as primeiras revistas científicas lançadas pelas Academias de Londres e de Paris em fins do século XVII, mesmo que de preferência destinadas aos pares espalhados nos quatro cantos da Europa, foi a um sistema virtualmente aberto que elas deram origem, caracterizado pela comunidade de discussão e o exame crítico das ideias, em continuidade a uma tradição já iniciada pelos gregos.

Todavia, nem os helenos, nem os romanos, nem os medievais tinham revistas científicas. Criação moderna por excelência, e junto com elas os artigos, o lançamento das primeiras revistas científicas só vai ocorrer nos séculos XVII e xviII, sendo a primeira o Journal des Savants, que data de 1665, deixando de circular quando da revolução francesa, para ser relançada décadas depois, porém com forte viés de revista literária. A segunda é a Philosophical Transactions of the Royal Society. Fundada um pouco depois no mesmo ano, a Transactions é a revista científica mais antiga do mundo anglofônico e é editada até hoje com a importante modificação introduzida em 1866, quando foi dividida em dois ramos: (A) ciências físicas; (B) ciências da vida. Possui a credencial de ter, senão criado o instituto da revisão pelos pares (peer review), ao menos criado a revisão editorial (editorial review), que lhe abriu o caminho. Dois anos depois, em 1666, foi a vez da revista Saggi di Naturale Esperienze, com grande impacto na comunicação dos resultados das discussões e descobertas protagonizadas pela Academia del Cimento [Experimentação] de Florença, à qual pertenceu Galileu e à qual a publicação era ligada.

É a partir desse background, com o formato, a vocação e os contornos bem definidos, que haverá a grande expansão das revistas científicas no século XIX: American Journal of Science (1818), Scientific American (1845), Nature (1869), Science (1880), e muitas outras, várias delas surgidas depois, no fim do século xx, como a Cell (1974) e a Neuron (1988). 
Às revistas soma-se a criação dos laboratórios científicos, no início públicos, com financiamento estatal, depois privados. A primazia cabe à Royal Institution, fundada em Londres no ano de 1799 e a quem cabe o reconhecimento de primeiro laboratório público de pesquisa, com o primeiro contingente de cientistas assalariados e um número expressivo de prêmios Nobel em seus quadros. Foi lá que foi gestada a primeira experiência do programa anual de conferências (lectures), de grande prestígio acadêmico e abertas ao público, que acorria aos seus salões para assistir às palestras de Faraday e de outros cientistas ilustres. Não de menos prestígio, e também franqueados ao público, serão os cursos e as conferências do Collège de France em Paris, com seus laboratórios, mas com outra vocação institucional, aberto às humanidades e visto como templo da ciência.

A história do sistema de comunicação da ciência ficaria incompleta, se não fosse mencionada a implantação do sistema de revisão pelos pares (peer review system), cuja data da criação é ainda matéria disputada. O sistema de revisão por pares ganha livre curso no século xx e converte-se em peça essencial do sistema de comunicação da ciência, de pronto adotado pelos editores de livros e revistas, bem como pelos comitês científicos de congressos e agências de fomento. O instituto, ou antes, o expediente, de fato data de séculos antes e já era conhecido desde a época histórica da fundação da ciência moderna, quando a Philosophical Transactions publicou seu primeiro editorial, de autoria de Henry Oldenburg, depois de examinado e aprovado pela Comissão Científica (Board). Então, conforme comentamos, se não era rigorosamente a revisão por pares, ao menos era a revisão pela comissão da revista, como ainda hoje acontece com muitas revistas, que entregam a tarefa da seleção dos artigos ao Comitê de consultores ad hoc, e até mesmo ao editor ou ao comitê editorial. Por sua vez, a primeira publicação inteiramente revisada pelos pares, ao que parece, foi a Medical Essays and Observations, veículo da Royal Society of Edimburgh, que data de 1731. Todavia, foi apenas na segunda metade do século xx que a revisão pelos pares passou a ter a importância e a universalidade que hoje lhe são reconhecidas, dando a impressão de que é inerente ao sistema e algo sacrossanto, e tornando suspeitas aquelas revistas e editoras que não seguem o modelo.

Certamente, em que pese a vasta aceitação, não faltaram as críticas e as desconfianças, e elas não tardaram a aparecer, como aquelas que atacavam o seu conservadorismo essencial; porém, não vamos tratar das críticas agora, mas no fim da exposição. Por ora, queremos registrar o seu nascimento e dar-lhe as boas vindas.

Por último, é preciso registrar aquelas que são as últimas e mais importantes criações do sistema de comunicação da ciência: as métricas e os indexadores, na opinião de muitos a companhia indesejável, mas não menos real e essencial, como veremos. Estas, sim, de fato e de direito, uma criação do século xx, quando foram inventadas as mais diversas métricas destinadas a medir a produtividade dos indivíduos, podendo essas métricas aplicarem-se a relatórios e patentes, 
bem como a livros e artigos, de modo que tudo passa a ser uma questão de número, indispensável para afastar o fator subjetivo dos julgamentos, e junto com os números foi criada uma profusão de tabelas, indexadores e curvas estatísticas. Assim, os mais conhecidos são: a base ISI (Institute for Scientific Information), que cobre oito mil periódicos, lançada em 1964 por Eugene Garfield e adquirida pela Thomson Reuters em 1992; a base Scopus, publicada desde 1992 pela Elsevier, o maior conglomerado do setor, e que cobre 19 mil periódicos, segundo o site da empresa; a base Social Sciences Citation Index (SSCI), publicado desde 1973 pela Thomson Reuters/ISI, cobrindo cerca de 1.700 periódicos de um conjunto de cinquenta disciplinas e recuando as referências até 1956; a base Arts and Humanities Citation Index (AHCI), também publicado pela Thomson Reuters, cobrindo cerca de 1.130 revistas e recuando as referências até 1975. E mesmo o Google Scholar, lançado em 2004, cobrindo os principais periódicos com revisão pelos pares da Europa e América do Norte, e distinto do seu irmão, o Google Books.

Há ainda um sem número de portais e bibliotecas eletrônicas, com destaque em nosso meio para o Portal da Capes e a Biblioteca da Scielo, assim como instituições e tradições direta ou indiretamente ligadas ao sistema de comunicação da ciência, como agências financiadoras, cátedras, prêmios, medalhas e outras honrarias, mas não vamos tratar desse ponto.

Ao invés, vamos introduzir e desenvolver na sequência outro tópico de suma importância que nos ajudará a completar o quadro, desestabilizando o sistema e turbinando a taylorização já iniciada. Trata-se do advento no curso do século xx da chamada big science, que é o resultado da fusão entre a ciência, a indústria e o Estado, à base de encomendas, projetos, consultorias etc., tendo como protagonista o famoso relatório Vanevar Bush (1945), que introduzirá o turning point da produção de C\&T nas quatro décadas que se seguiram ao fim da Segunda Guerra Mundial. Não menos do que nas políticas de governo, seu impacto sobre o sistema de comunicação da ciência será enorme, com consequências nunca vistas antes e em livre curso até hoje: a mercantilização do processo de geração e aplicação do conhecimento (ciência = negócios/produtos científicos = mercadorias), a privatização do conhecimento e a busca de vantagens competitivas (patentes, royalties, lucros), a concentração do mercado, a aceleração da atividade científica, a explosão das publicações, a modelagem de novas formas de gestão e controle das atividades e dos pesquisadores, a indução do "publique ou pereça" (publish or perish) e seus estragos terríveis.

\section{A big science e seu impacto sobre o sistema de comunicação da ciência}

Conhecido como o tempo das engenharias, o século xx elevou as ciências aos píncaros e extraiu de seus frutos toda sorte de vantagens e aplicações, não só engenhos e dispositivos materiais, mas processos e sistemas tecnológicos inteiros, operando a fusão entre o conhecimento e a indústria, incluída a agricultura, 
que se converterá em braço dela, encurtando a distância entre as nações e transformando a face do globo. Todavia, ao se ocuparem desse importante tópico, os estudiosos discreparam profundamente e forneceram as mais diferentes cronologias e os mais diversos nomes e pontos de corte.

Assim, Michael Mabe, ligado à Elsevier, em um importante artigo (Mabe, 2003), dirá que o século xx distingue-se por três fases. A primeira, de 1900 a 1940, a que ele dá o nome de "ciência inocente", ao longo da qual o aporte dos governos no financiamento da pesquisa é baixo, devendo o crescimento ocorrido nas quatro décadas ser creditado ao esforço dos cientistas e ao crescimento das disciplinas acadêmicas. A segunda fase, de 1944 a 1976, quando sobrevém a big science, expressão cunhada por Solla Price e do agrado de Mabe, caracterizada pelo investimento pesado dos governos em ciência e em tecnologia e o surgimento de editoras comerciais. E a terceira fase, de 1977 até os dias atuais, na qual impera a "ciência desiludida" (expressão nossa, baseada em indicações de Mabe), caracterizada pela queda relativa do investimento dos governos e tendo por contexto a crise do petróleo e o fim da guerra fria (Mabe, 2003, p.194).

Ziman (2004), por seu turno, falará igualmente de três fases, mas colocará $\mathrm{o}$ acento em outros fatos e processos sociológicos. Assim, a primeira fase, denominada "ciência acadêmica", que se inicia no século XIX, ou mesmo antes, e estende-se até 1920: trata-se de uma ciência gerada e consumida nas academias, consistindo num negócio dos cientistas. A segunda fase, de 1920 a 1980, a que Ziman dá o nome de "ciência industrial", que realiza a aproximação da ciência e da indústria e, junto com ela, a modificação da natureza da atividade científica, que se tornará mais e mais preocupada com resultados e aplicações, levando ao pragmatismo e impulsionando o utilitarismo. Na terceira fase, a partir dos anos 1980, que é a nossa época e à qual corresponde o que Ziman chama de "ciência pós-industrial", quando há o surgimento de uma ciência mais reflexiva, sociologicamente robusta (baseada em equipes de trabalho) e que é obra de cientistas atentos à responsabilidade social de seus atos, ante os resultados e às aplicações das ciências (Ziman, 2004, p.56-82).

Nossa proposta é a de reter de Mabe a expressão "big science", ficar com a segunda fase e deixar de lado a terceira (não é evidente que a era da big science e da ciência industrial tenha acabado), incorporando elementos da ciência pós-industrial de Ziman, porém com escopo e alvo diferentes ao introduzir os relatórios (accounts) e outros expedientes.

Sem mais delongas, diremos que o turning point que levará à big science tem uma data inequívoca e um documento testemunhal preciso, ambos citados por Ziman, a saber, o ano de 1945 e o relatório de Vanevar Bush (1945) por encomenda do presidente Roosevelt. Credenciais não lhe faltam, com efeito. Por um lado, ao impulsionar a criação de instituições importantes nos Estados Unidos, como a National Science Foundation (NSF), e definir as diretrizes das políticas públicas de C\&T no novo ambiente do pós-guerra, a publicação do 
relatório e a execução do seu plano de ação acarretarão a mudança das regras do jogo das relações entre a ciência, o governo e as empresas privadas por várias décadas. Algo aleatórias e soltas que eram, sem dar vazão a uma política continuada, essas relações passam a ser sistematicamente focalizadas em encomendas e projetos específicos, como tinha ocorrido durante a guerra com o projeto Manhattan e como ocorrerá mais tarde com o projeto Apollo. Por outro lado, ao redefinir o escopo e as relações com a academia, que será atraída ou, melhor, convocada a atender às demandas do governo, resultando nas parcerias com $\mathrm{o}$ Massachusetts Institute of Technology (MIT), o Caltech e inúmeras universidades de primeira linha. Este será o caso da Universidade de Chicago, na qual, "por volta de 1944, o orçamento anual tinha inchado, alcançando 31 milhões de dólares, três vezes o nível de antes da guerra. Desse total, 22 milhões vieram de contratos com o governo" (Waters, 2006, p.17).

A esse estado de coisas estamos chamando com Mabe e Solla Price de "big science", expressão à qual Ziman prefere "ciência industrial", e cujas principais características, variando a terminologia de um e de outros, são:

(1) A fusão entre ciência, economia e política ou entre ciência, indústria e governo (Estado): tal fusão acarretará, negativamente, o fim da ciência acadêmica e da idade da inocência e, positivamente, o surgimento da ciência industrial, às voltas com os interesses prosaicos e os negócios humanos, associada à criação do complexo industrial-militar nos Estados Unidos e à instalação dos programas de P\&D patrocinados por órgãos de governo e empresas privadas pelo mundo afora.

(2) A distinção entre ciência pura e ciência aplicada torna-se pouco pertinente e nada clara: a ciência industrial promove o advento das tecnociências ou, ao menos, o aprofundamento da simbiose entre a tecnologia e a ciência, convertendo-as num complexo único e num imenso colosso.

(3) A ciência industrial converte os produtos do conhecimento em mercadoria e a atividade científica num grande negócio: a big science exige o investimento de grande soma de capitais e vê no empreendimento científico um investimento de risco que deve ser compensado e remunerado (lucro); na big science haverá então o nivelamento e equalização entre o mercado de produtos e o mercado de ideias: "Não acredito que seja válida a distinção entre um mercado de bens e um mercado de ideias", sentencia Ronald Coase (1974, p.384-91) e com a aura de quem ganhou mais tarde, em 1991, o Nobel de Economia.

(4) Convertida em negócio, além da junção com a indústria, haverá a fusão da ciência com o mercado: trata-se da mercantilização do conhecimento (ideias $=$ produtos); assim, não é mais a cooperação desinteressada e a procura da verdade que governam a ciência, mas a concorrência e a busca do lucro, que combinam com o segredo e a busca de vantagens competitivas.

Tudo isso irá consumar-se na segunda metade do século xx, com seus vetores irresistíveis e suas consequências conhecidas. Por um lado, o aumento da 
escala da atividade científica e tecnológica, imperando o anonimato e a impessoalidade, junto com as incertezas e as desconfianças, num ambiente marcado pelo gigantismo e a opacidade. Por outro, o aumento da necessidade de controle e de auditagem, conduzindo aos relatórios e à burocratização dos processos: demanda de transparência e culto dos ritos procedimentais.

Os próprios números disponíveis atestam o gigantismo do estado de coisas e a amplitude dos investimentos requeridos, justificando o emprego da expressão "big science", bem como evidenciam o risco permanente de bancarrota que cerca a atividade científica e tecnológica, carregada de dúvidas e incertezas, podendo o esforço extenuante de anos após anos resultar em nada, e ao mesmo tempo aumentando mais e mais o laço entre economia e ciência, em busca de seiva (dinheiro) e de segurança.

A começar pelo número de cientistas. Sabe-se que o século xx gerou mais engenheiros e cientistas que todos os séculos precedentes somados ou reunidos. Todavia, é na segunda metade do século xx, mais estável e mais rico, sem a inconveniência das duas guerras que quase acabaram com a Europa, que haverá a mudança de escala e as cifras vão adquirir proporções impressionantes. Em levantamento referente ao período 2002-2007, a Unesco (2009) computou o crescimento de 5,8 a 7,1 milhões de pesquisadores no mundo, incluindo técnicos e engenheiros, e induzido, segundo a Organização, pelo grande incremento verificado nos países em desenvolvimento. A estimativa do número de cientistas é bem menor, e segundo certos cálculos teria atingido um milhão em 1990, aumentando significativamente depois, em paralelo ao forte crescimento mencionado acima. Por seu turno, na mesma direção, o montante do capital investido na formação de quadros de C\&T, no desenvolvimento de projetos e nas aplicações científicas e tecnológicas terá um crescimento exponencial e haverá igualmente a mudança da base e da escala das atividades.

Tomando como referência o relatório de Bush, na década de 1940 os investimentos em P\&D nos Estados Unidos não eram expressivos, com o governo federal respondendo por um quinto do total investido, atingindo em $1940 \mathrm{o}$ montante de US\$ 70 milhões, ou 1\% das despesas correntes, descontada a inflação. Passadas seis décadas, a NSF estima que a soma total dos investimentos em P\&D, computando investimentos públicos e privados, aqueles agora respondendo por uma porção maior, atingiram nos Estados Unidos em 2000 a espetacular cifra de 264 bilhões de dólares. Por sua vez, tomando o mundo como referência, o investimento total em P\&D foi estimado em 813 bilhões de dólares no ano de 2002, calculados com o método da "paridade do poder de compra" (NSF, 2008). Em 2006, segundo Duga e Studt (2007; 2008), tais gastos ultrapassaram um trilhão de dólares, ou seja, cerca de 2\% do PIB mundial. Em 2012, maior ainda... Reciprocamente, o desempenho da economia dependerá mais e mais de investimento em C\&T, gerando a sociedade do conhecimento e a "informacionalização" da economia. A contraparte, como já salientado, é a neces- 
sidade de remunerar o capital investido e proteger a propriedade intelectual das descobertas e aplicações: direitos autorais, patentes e royalties, de cujas injunções não vão escapar nem mesmo as universidades públicas, ao serem atraídas pela viagem sem volta do empreendedorismo e da inovação. Assim, desafiados pela situação de fato, os Estados Unidos vão criar o marco legal que dará a referência e a segurança que irão ao mesmo tempo incentivar e proteger aquelas instituições que aceitaram entrar no jogo dos negócios e do lucro. O marco foi criado em 1980 e passou a ser conhecido como Bayh-Dole Act (Castelfranchi, 2008, p.65ss.). Pois bem, ao aprovar tal lei, o Congresso norte-americano autorizou as universidades públicas a patentearem suas descobertas e invenções, bem como a concederem ou transferirem a sua exploração comercial exclusiva a empresas privadas, alugando ou vendendo os produtos do conhecimento, até então considerados de livre acesso e patrimônio da humanidade. Essa possibilidade de pronto será reconhecida e transformada em realidade no mundo inteiro, inclusive no Brasil e pelo governo brasileiro.

Contraparte do liame cada vez mais estreito e arriscado entre a ciência, a indústria e o mercado, com seus efeitos de retroalimentação capazes de gerar a causalidade circular dos processos que vai instaurar o sistema de C\&T\&I, cujos inputs serão alimentados pelos departamentos de pesquisa e desenvolvimento (P\&D) das empresas, pelas universidades e pelos editais de órgãos de governo, outro dispositivo da big science são as novas formas de gestão e controle dos processos intelectuais: às voltas com investimentos pesados, a mudança de escala das atividades, os custos altíssimos e o risco de não ter retorno algum, com os dólares saindo pelo ralo, as empresas e os órgãos de governo deram um jeito de auditar os processos, controlar os gastos e monitorar os cientistas - daí a proliferação de comitês de acompanhamento e avaliação, de órgãos de controle e auditorias, o sistema de recompensa e punição, os rankings de toda sorte.

Porém, por mais públicos que fossem, visando a garantia da impessoalidade e objetividade dos processos, esses dispositivos não propunham e não desfaziam o que estava a acontecer e com o qual eles vinham juntos: a mercantilização, o fim do ideal universalista e a privatização do conhecimento. De um só golpe, o ideal de abertura, de discussão ampla e compartilhamento dos resultados não tem mais vez e desaparece. Em seu lugar fica a competição cega e o carreirismo, a que se soma o enclausura mento da base de dados, dos processos e dos produtos do conhecimento, além do elevado custo das revistas científicas mundiais e sua concentração nas mãos de poucos editores, tais como Elsevier, Springer e Wiley-Blackwell, às quais voltaremos na sequência.

Tal situação é amplamente conhecida, mas incompleta. Será preciso acrescentar mais duas outras notas para que a big science mostre seus efeitos por inteiro, ao impactar aquilo que estamos chamando de sistema de comunicação da ciência. Com o sistema vascularizado pelo money e pela inversão de somas altíssimas de capitais, marcadas pelo mal infinito da fuite en avant, como dizem os 
franceses, haverá a inflação do conhecimento e das publicações, acompanhada de seu par indesejado, mas reparador, a obsolescência programada dos resultados das pesquisas e dos artefatos tecnológicos. Os números que evidenciam a inflação são estonteantes e serão fornecidos daqui a pouco para os livros e os artigos. Quanto ao descarte - sem poder no plano conceitual endossar a famosa "destruição criadora" em que Schumpeter viu a essência do progresso técnico capitalista, pois o que está em jogo é a entropia bruta -, a obsolescência aumentou desmesuradamente, alavancada pelo engolfamento do sistema. Como no Crash de 1929, quando o Brasil foi condenado a queimar literalmente todo o café estocado nos armazéns, acarretando a destruição pura e simples, a destruição nada criadora, o mesmo se dará com outros bens assim como as ideias, agora em tempos normais e em conjunturas mais favoráveis, levando a revista inglesa The Economist (fev. 2007) a perguntar a respeito da medicina: "por que tanta pesquisa médica é podre (rot)?”.

Expostos às pressões avassaladoras de publicar e descartar, as quais parecem não ter fim, do lado dos cientistas e pesquisadores impera o "publicar ou perecer" com sua capacidade de causar estragos terríveis nos meios acadêmicos, destruindo reputações, criando falsos heróis e gerando todo tipo de distorções, como a precipitação das publicações e o fatiamento da produção (técnica do salame). Então, com o surgimento da big science, junto com essas distorções e esses ilícitos, de resto não aleatórios mas sistêmicos, é o fim do éthos da ciência acadêmica, cujo perfil foi traçado por Robert K. Merton, que será consumado e, mesmo, celebrado. Pautando-se não mais pelo dever-ser da norma estrita e o valor incondicional da verdade e do bem comum, a conduta será medida pelos resultados, pela rentabilidade dos processos e a vantagem competitiva advinda dos monopólios, das expertises e das novidades. Como qualquer homem de negócio, os cientistas podem ser empresários e vender suas descobertas; os docentes de humanidades e ciências sociais podem dar consultorias a empresas e órgãos de governo; tudo em princípio tem preço e pode ser comercializado. A consequência é conhecida e a ela voltaremos mais de uma vez: no lugar do éthos tradicional da busca desinteressada pela verdade e do conhecimento pelo conhecimento, fica o conhecimento interessado e a atitude calculista, focalizada nos resultados dos processos e na utilidade das coisas, resultando em uma ética utilitarista, também chamada de "consequencialista" pelos estudiosos.

A esse conjunto de coisas estamos dando o nome de "taylorização acadêmica".

\section{Características da taylorização acadêmica}

Por taylorização entendemos, portanto, o processo ligado à fusão do conhecimento e da indústria que termina por submeter a ciência e a pesquisa às leis do mercado e aos modos de gestão das empresas capitalistas. Três são os vetores:

(1) a abertura e a democratização dos processos cognitivos e intelectuais: o mercado é, em princípio, aberto e franqueado a todos os indivíduos, mas há distorções; 
(2) a dependência da indústria e do capital do emprego de tecnologias intensivas e, portanto, das descobertas e aplicações das ciências;

(3) a transformação da ciência e seus produtos em negócio e do cientista em empresário ou em empregado, associada à expansão da indústria cultural e do próprio turismo, permitindo a multiplicação de eventos e, por extensão, de atas de congresso e de artigos.

Desde então, em grande medida, e não estamos querendo ofender ninguém, estamos apenas juntando os fatos, o taylorismo intelectual e o turismo acadêmico vão juntos.

Ao promover a equivalência entre o mercado de bens e o mercado de ideias, a taylorização faz do crescimento da riqueza o norte do sistema, função da redução dos custos da produção e do aumento da produtividade. Levada às universidades, aos institutos de pesquisa e aos laboratórios das grandes corporações, a taylorização promoverá por toda parte o aumento constante dos investimentos em P\&D, a expansão da base física do sistema (laboratórios, instituições, número de cientistas), a aceleração do conhecimento e a explosão das publicações. Tendo já ressaltado os grandes números da big science à qual está associada, passaremos a fornecer na sequência as cifras da taylorização acadêmica, abarcando os periódicos, os artigos e os livros.

Começando pelo número de periódicos indexados, é grande a discrepância entre as bases mais conhecidas. A IPD da Ulrich refere-se a 250 mil; a BLDSC da British Library, a 40 mil periódicos em circulação, contra 170 mil fechados; Antilope (Bélgica) a 150 mil. Embora analiticamente mais bem equipados do que as instituições que lhes proporcionam as bases, os estudiosos estão longe de nos fornecer números depurados e consensuais, e as discrepâncias não poderiam ser maiores. Segundo Bennion, ninguém conhece o número exato, mas podem existir vinte mil ou mais revistas científicas. Já Goodstein estima esse número em cerca de quarenta mil. Tenopir e King dizem que poderiam ser "entre 80.000 e 100.000". Por fim, Meadows conta 71 mil, enquanto Mabe (2003, p.192), tomando como critério o sistema de revisão pelos pares, fala em 14.694 revistas (Mabe, 2003, p.191; Castelfranchi, 2008, p.57ss.).

Passando aos artigos, com seu universo consideravelmente maior, a situação piora e as incertezas aumentam, porém nem por isso ficamos impedidos de fazer uma ideia da grandeza e mesmo da inflação desse prestigiado gênero de publicação. Assim, a considerar o número de artigos por ano, e variando os parâmetros adotados, teremos Mabe (2003, p.191) com um milhão (revistas que adotam o sistema de revisão por pares) e Jinha (2010) com cinquenta milhões (número total de artigos publicados até 2009, desde 1665, quando a Philosophical Transactions da Royal Society foi lançada). Quanto ao número de livros, não são menores as discrepâncias, nem a profundidade das controvérsias. Tudo depende do que consideramos o que é um livro: autoral? ISBN? tomo? etc. - e aí as coisas complicam. Leonid Taycher (2010), tomando como referência databases 
operadas pelo Google, fala em 129.864.880 de obras únicas ou originais, sobre um universo de 600.000.000 de registros. Waters, com a credencial de editor de humanidades da Harvard University Press, porém com um escopo menor (mundo anglofônico), registra um grande crescimento do lançamento de livros nas principais editoras universitárias americanas e inglesas, citando estudo de Willis Regier: "Nos últimos vinte anos, dobrou o número de novos livros publicados pela[s] editora[s] das universidades da Califórnia, Columbia, MIT e Princeton; nas universidades de Indiana e Yale, o número triplicou; e, em Stanford, se multiplicou por seis ... Em 1980, a editora da Universidade de Cambridge publicou 543 novos títulos e a de Oxford, 802. Em 2000, Cambridge publicou 2.376 novos livros, e Oxford, 2250 ... O total de lançamentos de todas as editoras universitárias, em 2000, foi de 31 milhões de livros" (Waters, 2006, p. 14).

Até agora, com a intenção de dar ao leitor uma ideia dos grandes números da taylorização acadêmica, ficamos apenas com as grandezas absolutas, expediente necessário, mas insuficiente. Será preciso ainda mostrar as tendências profundas do sistema e as séries históricas, mesmo que estorvados pelos dados primários controversos e pouco acurados. Atentos a isso, trabalhando séries históricas mais longas, os especialistas em cienciometria conseguem fornecer os números que atestam uma taxa de crescimento constante tanto de revistas quanto de artigos, chegando a duplicar a cada vinte anos.

Assim, Solla Price (1975, p.167), pioneiro dos estudos, tomando como ponto de partida a Philosophical Transactions, descobriu a existência de um crescimento exponencial das revistas, entre 1700 e 2000. Mabe (2003) fornece a taxa do aumento exponencial detectado por Solla Price: $3,46 \%$ a.a. Tal cifra não poderia ser mais significativa e convincente: crescer a essa taxa constante por ano significa justamente que o número de revistas ativas duplica a cada vinte anos (Mabe, 2003, p.193).

Há ainda outros dados de Mabe em que encontramos as taxas de crescimento que nos interessam mais de perto, o século xx, segmentado em três fases e tomando como referência o lançamento de revistas científicas. Assim, na primeira fase, da "ciência inocente", de 1900 a 1940, as revistas crescem 3,23\% ao ano e dobram seu número a cada 22 anos; na segunda fase, da big science, de 1944 a 1976, há um crescimento de 4,35\% ao ano e o número de revistas dobra a cada dezesseis anos; finalmente, no período da "ciência desiludida", de 1976-1977 até os dias atuais, há um crescimento de 3,26\% ao ano e o número de revistas dobra em aproximadamente 22 anos, como na primeira fase (Mabe, 2003, p.194).

Mais uma vez os números eles mesmos, tomados isoladamente, dizem muito pouco, e para mostrar o que eles significam devem ser interpretados. Bem pesadas as coisas, não é fácil interpretar os dados que eles agregam, as forças que atuam no sistema e as tendências dos anos que virão. Terá ocorrido uma explo- 
são das publicações devido ao aparecimento e à potenciação de novos veículos, como os e-books e as revistas eletrônicas? Mabe $(2003$, p.196) pensa que não, e suspeita que o nexo causal pode ser de outra ordem e estar ligado a outro fator.

Para demonstrar seu pensamento, ele se apoia na correlação entre o crescimento do número de cientistas, do número de revistas e do número de artigos, tomando como referência o período 1981-1995. Sua conclusão é que não apenas a conexão entre o crescimento do número de títulos de revista e o crescimento do número de pesquisadores, e, por extensão, do número de artigos, não deixa dúvida, mas também que cada revista criada "pode ser vista como o resultado sociológico de um novo agrupamento de pesquisadores" (Mabe, 2003, p.195), fator esse muito comum nas mais diferentes academias e áreas profissionais em qualquer lugar do mundo, diga-se.

Por seu turno, atento à ação de outros fatores, Castelfranchi (2008) mostra que o volume do crescimento em grande medida dependerá da base de dados utilizada: Scopus, ISI ou Citation Index, que estão longe de cobrir tudo, deixando de fora um volume expressivo de publicações das humanidades. No caso do ISI, “em 2008, eram cerca de oito mil e setecentos os periódicos indexados no ISI (dos quais pouquíssimos brasileiros). Embora esse número cresça de várias dezenas a cada ano, seu aumento não é exponencial, porque limitado pela seleção efetuada pela própria equipe da ISI" (Castelfranchi, 2008, p.58). Em consequência, outras contas deverão ser feitas para melhorar a acurácia.

As coisas não param aí. Ao promover a fusão da ciência, da indústria e do Estado (programas de governo), a big science, e junto com ela a taylorização, dará vazão às forças cegas que atuam na economia, instalando a concorrência nos meios acadêmicos e levando à concentração do mercado. Tal será o caso das revistas e dos livros.

Castelfranchi (2008, p.58) argumenta que

[...] a estimativa é de que apenas três mil revistas no mundo hospedam $75 \%$ dos papers que são publicados no planeta e $90 \%$ daqueles que acabam sendo citados por alguém (trata-se da chamada "lei de Bradford"). Um número ainda menor de jornais [revistas], trezentos, publica a metade de tudo que no mundo é citado por alguém.

Com efeito, a lei de Bradford é venerada em bibliometria pelos seus serviços de medir a produtividade das revistas, evidenciando seu crescimento, decrescimento ou estagnação. Porém, no tocante aos processos ligados à big science e seu impacto sobre o sistema de comunicação da ciência, com suas distorções e seus efeitos concentracionistas, em vez de niveladores ou distribucionais, talvez o "efeito Mateus" tipificado por Merton ("Quanto mais, mais") seja mais pertinente e aquele fator que jogue mais luz sobre o estado das publicações e dos artigos em um ambiente de ciência taylorizada (Merton, 2013, p.204-5, nota 3).

Sobre o tal efeito, a ele está associado e constitui um de seus principais vetores o selo de prestígio das editoras e dos periódicos. Markus Meister, reno- 
mado biólogo, cita como exemplos de revistas de primeira linha de sua área $\mathrm{Na}$ ture, Science, Cell e Neuron (Waters, 2006, p.28), verdadeiros ícones e sonhos de publicação de qualquer pesquisador. Sem dúvida, esse ponto é importante, e deve ser considerado não só pela visibilidade que o prestígio gera a todo aquele que vence a barreira do anonimato, mas também pelas distorções e as iniquidades que o acompanham, como veremos.

Nada é, todavia, comparável às pesadas distorções e aos efeitos em cascata do poder econômico sobre o mercado editorial, gerando a concentração das revistas e da indústria do livro nas mãos de poucas editoras, além do viés linguístico, com o inglês - língua de cultura dos ingleses e norte-americanos - convertendo-se em língua franca. Um excelente exemplo é o grupo Elsevier que, sediado na Holanda, é o gigante do setor, com o portfólio de duas mil revistas e vinte mil livros, cobrindo C\&T e ciências da saúde, e empregando sete mil pessoas em 24 países, sete mil editores de periódicos, setenta mil membros de comitê editorial, trezentos mil pareceristas ad hoc e seiscentos mil autores. Outros gigantes são a Springer, da Alemanha, com a credencial de maior editor de livros do mundo: 6.500 novos títulos por ano, e o segundo de revistas: cerca de dois mil, e o aglomerado Wiley-Blackwell, dos EUA, com cerca de 1.500 revistas com revisão pelos pares em seu catálogo e mais de 1.500 livros novos por ano.

Sumariando, o sistema taylorista instala, pois, a ratio econômica na produção industrial, inclusive na agricultura, que se converte em ramo da indústria, e estende seus expedientes e dispositivos ao mundo intelectual, assim como aos processos de produção e difusão do conhecimento. Dois são os vetores da ratio taylorista:

(1) a divisão parcelada do trabalho, gerando a dispersão dos processos e a especialização dos indivíduos;

(2) a instituição de corpo de gerentes e administradores para monitorar os processos e vencer a segmentação, colocando os indivíduos a serviço do todo ou da empresa.

Uma coisa não vai sem a outra no plano das causalidades, ao passo que será um único o fim do processo, ou seja, o aumento da produção e da produtividade, que é igual ao direito e ao avesso de uma mesma realidade.

Nas fábricas e nas academias, haverá a mudança de escala e de patamar das atividades, que ficarão mais complexas e, na mesma proporção, menos intuitivas. Aqui e lá, para o acompanhamento e controle, não basta mais o senso comum e a experiência acumulada, mas será preciso buscar ajuda na ciência e em suas ferramentas analíticas, como as métricas matemáticas e as tabelas estatísticas. Tal necessidade levará à criação nos órgãos de governo e nas academias de um staff administrativo especializado, o qual ganhará importância ao longo do tempo, dando a impressão de que a ciência e a atividade científica não poderiam passar sem ele. Trata-se de uma ciência "auditada" e junto com a comunidade científica 
uma verdadeira sociedade de auditores foi criada... para controlar a ciência e o cientista. Voltaremos a esse ponto na sequência.

Antes, porém, será preciso considerar as distorções sistêmicas e as inversões de valores que acompanham e nucleiam a ratio taylorista. Ora, o taylorismo acadêmico, a exemplo do seu congênere econômico, mede o processo pelo produto e visa o aumento da produtividade do trabalho intelectual, cujos produtos mais nobres são artigos e livros. No caso das ciências, visa-se prioritariamente a produção de artigos, os quais, por serem fáceis de contar, são mais facilmente apropriados pela ratio taylorista, levando à "paperização" do conhecimento: os artigos podem ser anualizados e coincidir com o ano civil, facilitando a visualização da produção ao longo do tempo, bem como sua indexação e a aferição dos índices de impacto. Isso tem implicações para o entendimento da significância dos artigos e permite que eles sejam usados para fins que pouco tem a ver com a atividade de aprofundamento do conhecimento científico, tal como se expõe a seguir na seção que segue.

Não é preciso muito para mostrar que a alma do taylorismo acadêmico é o "publique ou pereça". Trata-se de um princípio agônico, baseado no tudo ou nada dos jogos perigosos de vida e morte, como nas antigas ordálias. Seus principais traços, modus operandi e resultados são amplamente conhecidos. Por um lado, transforma a produção intelectual em um grande certame, como nos plays-offs, dividindo o mundo entre vencedores (produtivos) e derrotados (improdutivos). Ademais, promove a troca da qualidade pela quantidade, a profundidade pela velocidade e o mérito pela performance (índice de impacto). E por toda parte instala o tempo acelerado, mede o talento pelo produto e leva ao produtivismo ou à produção pela produção como valor e atitude. Por outro lado, quanto aos resultados, o taylorismo acarreta o fim da criatividade e da fantasia, trocando a invenção e o risco pelos relatórios e pelo controle, uma consequência é a estandardização e a burocratização dos processos, cujos efeitos negativos são lamentados e ao mesmo tempo buscados com insistência e sofreguidão. Outra consequência é o conservadorismo: ninguém arrisca nada; passamos a maior parte do tempo fazendo relatórios, administrando a carreira e fabricando artigos do que desenvolvendo a pesquisa e cultivando o intelecto.

Não é à toa que num quadro como esse, onde a fantasia foi banida, a criatividade é vigiada e o conservadorismo impera, vão aparecer aqueles críticos que irão assacar contra a taylorização acadêmica, ainda que sem usar o nome, a pesada acusação de provocar o suicídio do intelecto e a morte do pensamento. Tal vai ser o caso dos signatários do manifesto Slow Science, liderado por Jonas Obleser, do Instituto Max Planck, da Alemanha, que se insurge contra o produtivismo e a aceleração dos processos e propugna que a ciência precisa de tempo: "para pensar, digerir e para fazer seu trabalho" (Slow Science, 2010).

$\mathrm{Na}$ sequência vamos passar às críticas da ratio taylorista e indagar pelas saídas. 


\section{Críticas à ratio taylorista e saídas}

Dissemos no início que o taylorismo tem uma forte incidência na gestão e administração da indústria, implicando na busca sistemática da racionalização dos processos - do chão das fábricas aos escritórios, primeiro, e da indústria às academias, depois, ao se proceder a fusão da ciência, da economia e da política (estado ou governo).

Trata-se de uma techne, em suma, cujos princípios serão buscados na ciência (o título do livro famoso de Taylor (1911) refere-se justamente à "administração científica"), autorizando a aproximação da ratio taylorista daquilo que os weberianos chamavam de "racionalidade burocrática" e os frankfurtianos de "razão instrumental". Porém, algo mais está em jogo.

Por ratio taylorista entendemos a fusão da razão matemática e da razão econômica, fundada em métricas e em cálculos, bem como em valores e regras de conduta talhados por uma psicologia behaviorista e uma ética utilitarista, além de modelados - em um ambiente de demanda crescente por relatórios e boas práticas, visando o maior controle dos processos - pelas normas e procedimentos do direito.

Então, tendo suspeitado desse casamento, os críticos da ratio taylorista não tardaram a tomar como alvo dos seus ataques os princípios, as métricas e os procedimentos que a lastreiam e conduzem às distorções e perversões do sistema.

Um dos primeiros alvos do ataque foi o princípio que baliza o sistema, a saber, a equivalência funcional estabelecida por Coase entre o mercado de produtos e o mercado de ideias. Equivalência enganosa e redutora, pois dir-se-á que a ciência e seus resultados não são essencialmente produtos ou mercadorias, ainda que possam ser comercializados e gerar lucros fabulosos, mas um bem da civilização e um patrimônio da humanidade. "A ciência não tem dono nem pátria", dizia Pasteur (apud Merton, 2013, p.188). Contra tal equivalência e a ideia a que está associada, a saber, a crença de que o mercado promove-lhes o encontro e os fomenta, introduzindo o círculo virtuoso, Joseph Stiglitz, Nobel de economia em 1991, mostrará que ela não tem o menor fundamento, pois "o que eles [os mecanismos de mercado] realmente fazem é produzir as pressões que aumentam a produtividade" (Stiglitz apud Waters, 2006, p.17).

Outro alvo dos ataques são as métricas. O grande argumento a favor delas é que todo sistema de avaliação, acompanhamento e controle só é possível com a ajuda de métricas, as quais vão permitir as comparações e garantir a impessoalidade. Se continuássemos a enquete, certamente acharíamos outros serviços, e poderíamos endossar a fórmula de lord Kelvin que assim resume a opinião "oficial" a respeito da importância delas: "quando podemos medir aquilo que estamos falando, e expressá-lo em números, sabemos algo a seu respeito; mas quando não podemos expressá-lo em números, nosso conhecimento é pobre e insatisfatório" (Kelvin apud Waters, 2006, p.16). 
Os argumentos contrários são de várias ordens, incidindo sobre a ilusão da objetividade e o grande tour de force que elas promovem ao medir a qualidade pela quantidade. Einstein dizia que "nem tudo que é importante pode ser medido", ${ }^{2}$ por exemplo, a moral e a reputação das pessoas. Mas não é o que muitos pensam, dentro e fora das ciências, não escondendo sua desconfiança quanto às críticas ("subjetivas") e devotando às medidas uma veneração quase religiosa. Mais do que ferramentas para descrever os processos, as métricas convertem-se em princípios normativos, vendo crescer seu poder e raio de ação. É aí que reside a ilusão e de onde vêm os males. Ao fim e ao cabo, na raiz do encantamento pelas métricas e da disposição de seguir suas implicações sem questionamento, como se elas por si só gerassem as normas e tomassem as decisões, está o fetichismo dos números e uma atitude acrítica. Daí as cifras para tudo e a tendência de trocar os relatórios e julgamentos por algoritmos automáticos: ninguém precisa ler artigos que não entende e que são fabricados em escala industrial, basta contabilizá-los. Conforme viu Platão no Eutifron, ali onde falta a régua para medir as coisas e afastar as dúvidas impera a discórdia e a discussão sem fim, como no mundo da opinião. Todavia, as métricas estão longe de ser inocentes e seus usos, ou antes mau usos, podem provocar as mais graves distorções.

É o que mostra Peter Lawrence, professor de zoologia de Cambridge, na seguinte passagem onde ele expressa sua profunda reserva face às medidas:

A mensuração da produtividade científica é difícil. As medidas usadas (fator de impacto da revista, citações do artigo que está sendo medido) são cruas. Mas estas medidas são tão universalmente adotadas que elas determinam muitas coisas que importam [para os pesquisadores]: estabilidade ou desemprego, uma bolsa de pós-doutorado ou nenhuma, sucesso ou fracasso. Em consequência, os cientistas têm sido forçados a rebaixar seus objetivos primários de fazer descobertas, com o propósito de publicar tantos artigos quanto possível e tentar publicá-los em revistas de alto impacto. Consequentemente, a atitude científica tornou-se distorcida, e a utilidade, a qualidade e a objetividade dos artigos têm deteriorado. Mudanças [...] são requeridas com urgência, e eu sugiro algumas aqui. (Lawrence, 2008, p.9)

$\mathrm{Na}$ esteira das métricas, não vão tardar as críticas aos rankings, que são um tipo de métrica. Lawrence (2003) estampa suas reservas em face da proliferação dos rankings acadêmicos que, além das universidades, classificam as revistas em níveis ou estratos A, B, C, como ocorre entre nós com o Qualis da Capes. Tais rankings, assim como as métricas, integram o mesmo processo das sociedades contemporâneas com suas demandas de relatórios e auditagem das informações, levando à proliferação de peritos e auditores. "O resultado é uma 'sociedade de auditores' em que cada indicador é investido com uma especial acurácia e torna-se um fim em si mesmo" (Lawrence, 2003, p.259).

Um ano antes, Lawrence já se insurgira contra as distorções produzidas pelos rankings, denunciando o descompasso entre o processo de descoberta 
científica e os efeitos das classificações em termos de política científica e de fomento. Pergunta ele de saída: "o que tem a classificação a ver com o processo de descoberta criativa em ciência? Muito pouco. O que a classificação tem a ver com políticas de ciência e a alocação de recursos para as descobertas? Quase tudo" (Lawrence, 2002, p.835). ${ }^{3}$

$\mathrm{Na}$ mesma linha, Ellen Hazelkorn (2008, p.18), ligada ao Instituto de Tecnologia de Dublin e coordenadora de uma pesquisa da OCDE sobre rankings, declarou em uma palestra em 2008 que "os rankings causam grandes danos ao induzir instituições de ensino superior e governos a adotar soluções simplistas e a distorcer agendas e políticas de pesquisa para que elas se tornem aquilo que é medido". Consideramos essa observação da irlandesa, além de sagaz, certeira em seu alvo, pois, de fato, além de trabalharem com indicadores que não são capazes de medir o leque completo das atividades das grandes universidades, os rankings terminam por introduzir um viés em favor de disciplinas científicas, biomédicas e tecnológicas, encorajando as instituições a tornarem-se aquilo que elas medem. Ou seja, uma usina de artigos, bancos de dados, patentes, serviços e desempenhos contabilizáveis, referenciados ao ano civil, alimentando a concorrência dos indivíduos e turbinando o taylorismo acadêmico. Em contraste, segundo Hazelkorn, todas aquelas instituições que discrepam e se afastam do padrão ou não têm a sua "cara" serão subavaliadas ou desvalorizadas.

A essa situação, tão bem caracterizada por Lawrence e Hazelkorn, somam-se a precipitação e a inflação das publicações, tornando impossível a comunidade acompanhar o que se passa ao redor e forçando a aplicação de algoritmos automáticos, sem ler e avaliar verdadeiramente o que o colega produz ou produziu. Acrescentem-se ainda as distorções geradas quando se passa da avaliação do indivíduo para agregados maiores e a instituição como um todo, e vice-versa. Então, é todo o sistema de avaliação e acompanhamento que será terceirizado, dispensando o julgamento pessoal e transformando a objetividade e a contabilidade dos processos e das métricas num verdadeiro embuste.

Generalizando, se juntamos aos rankings e às métricas o sistema de revisão por pares e outros expedientes de acompanhamento da pesquisa acadêmica, o resultado será aquilo que Peter Lawrence chamou com Michael Power (1997, cap.1, 6) de "sociedade de auditores", já referida e à qual voltamos.

Trata-se, com efeito, da face mais temerária da taylorização, onde as métricas e os rankings convertem-se em instrumentos de controle e auditagem, estendendo-se às contas e aos atos de governos, bem como das universidades e academias, e resultando na instauração do já citado poder paralelo mediante a criação de um corpo administrativo separado e acima dos cientistas, pesquisadores e governantes. Só recentemente etiquetado, o nome desse corpo e poder varia, chamados de "sociedade de controle" pelos deleuzianos e mesmo foucaultianos, "sociedade auditada" por Power e "cultura auditada" por Strathern. Atento 
ao mesmo fenômeno nas universidades e academias, Lawrence não esconde a sua preocupação, estabelecendo o liame entre os accounts e as implicações políticas, ao afirmar no já referido artigo de 2003 que “os administradores estão roubando o poder dos cientistas e construindo uma cultura de contabilidades que "visa a um controle administrativo ainda mais perfeito da vida institucional e profissional" ", cujo resultado é a "sociedade de auditores" e ao qual poderíamos chamar de "universidade auditada". Assim, fica claro que as métricas e os accounts não são nada inocentes, podendo converter-se em poder e meio de poder, e cujo perigo já tinha sido antevisto por Talcott Parsons e Gerald Platt (1973) tempos antes no celebrado livro sobre a sociedade americana. Segundo eles, a criação desse corpo caracterizado pela alta "racionalidade cognitiva" terminaria por prejudicar a universidade, porque por dever de ofício e questão de valor iria privilegiar "a burocracia mais simplificada”, e não os cientistas e pesquisadores, poderíamos acrescentar. (Waters, 2006, p.17-18).

Passando ao sistema de revisão pelos pares, tão venerado pelos editores dos periódicos e pelos próprios pesquisadores ansiosos por mecanismos fiáveis na seleção dos artigos a serem publicados, as críticas e as desconfianças não são menores, mas é preciso cautela no seu endosso e acolhimento. Antes de mais nada, é preciso convir que o sistema de revisão por pares não é taylorista de nascença, e a prova é que ele foi criado antes, muito antes, no século XvIII; contudo, ao ser apropriado pelo sistema taylorista, ele será turbinado e ao mesmo tempo proporcionar-lhe-á grandes serviços.

A grande vantagem do sistema de revisão pelos pares é o selo de confiabilidade que imprime às revistas e aos artigos, graças ao trabalho paciente e dedicado de experts das mais variadas áreas do conhecimento. Por outro lado, as críticas são de várias ordens, e nem sempre, ao ser visado, o sistema taylorista é atingido. As principais são:

(1) O sistema de revisão pelos pares é lento, a demora podendo chegar a meses, e mesmo a um ano, até que finalmente o parecer chegue às mãos do editor, e nem sempre um parecer conclusivo; (2) o sistema não afasta o fator subjetivo e as idiossincrasias, podendo os preconceitos fazerem estragos terríveis sob a capa do anonimato; (3) o sistema não é um trabalho remunerado, por isso o avaliador tende a investir pouco tempo no exame de um artigo; (4) o sistema, fundado na expertise disciplinar, não funciona para pesquisas inter ou multidisciplinares, e nem sempre basta o expediente de dupla expertise; (5) o sistema não permite operar a contradição, visto que os referees não interagem e não tomam conhecimento uns dos outros: a solução ficará com o tertius (e será meramente numérica) ou então com o comitê ou o editor (e será política); (6) o sistema é conservador, favorecendo a publicação de artigos cujos argumentos e ideias estão de acordo com o mainstream e a opinião dos experts e, inversamente, desfavorecendo aqueles que discrepam, pegam as coisas pelo avesso e têm um potencial desestabilizador e revolucionário. 
Todas essas críticas, a maioria proveniente de Waters que faz um excelente apanhado delas, têm a sua razão de ser e de fato são preocupantes. Todavia, o sistema tem outros lados e sua montagem respondeu a situações e demandas nada triviais que desafiavam a comunidade acadêmica: por um lado, o gigantismo das áreas, a ultraespecialização disciplinar e a inflação das publicações - donde a importância da opinião do expert, e na impossibilidade de ter a opinião de todos é melhor ter a opinião de um ou de dois e fazer-lhes confiança do que de nenhum; por outro, a necessidade de garantir a todos a impessoalidade dos julgamentos, proporcionada pelo expediente adicional e complementar da avaliação às cegas, e melhor ainda no sistema duplo cego. O grande erro - este, sim, uma distorção que em si mesma não é da natureza do sistema, a exemplo das métricas, cujas distorções também não lhe são inerentes, mas devem ser creditadas às falhas dos indivíduos - aparece ao procurar-se no sistema aquilo que ele não pode oferecer, isto é, tomar a revisão pelos pares como garantida da validade, do ineditismo e da relevância de um artigo ou de um achado, e não de sua "aceitabilidade" ou "correção" (métodos e dados).*

Mais sérias ainda, todavia, são as críticas dirigidas ao "publique ou pereça”, e mais sérias porque elas atingem o coração do sistema ou a sua alma, ao dar vazão à pressão por mais publicações. Tal animus, além de motor do sistema taylorista, fornecendo-lhe a preciosa seiva sem a qual ele não pode viver, acarretará graves distorções, como já antecipamos:

(1) Instala a competição cega e conduz ao enlouquecimento do sistema, sistema que, até mesmo evolucionariamente, não pode funcionar sem alguma base cooperativa, e a qual fica reduzida a quase nada e tem uma atuação combalida.

(2) Dissemina as fraudes e os plágios, nas suas mais variadas formas, e induz à precipitação, à corrida para chegar primeiro.

(3) Incita o tempo acelerado que se estende ao infinito e não combina com o tempo humano e os altos e baixos da criação, podendo uma obra de talento ou de gênio passar despercebida, demorar décadas até ser descoberta, e não ser capturada pelos índices de impacto.

Essa é a face escondida ou invisível do sistema, ao denunciar o estrago da corrida pelas publicações, evidenciando o espetáculo de artigos mal talhados e escondendo os verdadeiros tesouros que o sistema não consegue capturar ou que foram simplesmente deixados de lado, como no caso de Mendel. A face visível e nada lisonjeira, capaz de minar a credibilidade do sistema naquilo que ele tem de mais precioso e de mais caro, vai ser encontrada não naquilo que o sistema esconde, mas mostra por inteiro nos escândalos das fraudes, dos plágios

* Sobre esse ponto, ver Horton, 2000, p. 148-9, onde ele conclui suas análises dizendo, ao contrário, que o sistema de revisão por pares é "biased, injust, unaccountable, incomplete, easily fixed, often insulting, usually ignorant, occasionally foolish, and frequently wrong”. Assinale-se que Horton é editor do British Medical Journal The Lancet, considerado referência na área médica. 
e dos arranjos ilícitos, abarcando toda sorte de expedientes para melhorar o desempenho dos pesquisadores e dos veículos, desde as combinações das citações, passando pela técnica do fatiamento da produção (técnica do salame), até a maquiagem e a invenção dos dados ou achados.

O resultado desses ilícitos e distorções, não podendo ser colocados exclusivamente na conta dos indivíduos, deverá ser estendido ao sistema inteiro, a evidenciar que algo mais grave está em curso, capaz de partir ao meio o arrimo que sustenta e protege o edifício. $\mathrm{O}$ arrimo não é senão o éthos da atividade intelectual e está-se a falar justamente da sua fratura: a fratura do éthos da ciência acadêmica no sentido de Merton (2013), já tratado por nós em outras oportunidades, e agora ao emparelhar produtivismo e carreirismo, por um lado, e formalismo e utilitarismo, por outro. Daí o culto dos procedimentos e dos relatórios não tendo outro horizonte senão a eficiência e a transparência dos processos, num mundo que de repente ficou agigantado e impessoal demais, em que a virtude dos cidadãos não conta ou foi banida e em que devemos nos socorrer na moral utilitarista, que é uma ética das consequências e da exterioridade dos atos, quando justamente é a confiabilidade deles que está em jogo.

Pergunta-se por que isso aconteceu - por que as virtudes e os interesses não bastam e por que pedir accounts para tudo? Porque tudo ficou opaco, houve a quebra da fé e ninguém confia mais em ninguém - responderá Power (1997, p.135-6).

\section{O que fazer? Qual é ou há de ser a saída?}

Se pudéssemos resumir tudo numa só frase, diríamos que a alma do sistema taylorista é o "publicar ou perecer", sua ratio é o quantum, seu método, as métricas, e seu corpo ou matéria é o artigo científico. Tão naturalizado está o sistema e tão legitimado o conjunto desses dispositivos e expedientes, com a chancela da ética e do direito, que a impressão restante é de fatalidade ou de destino, ou então de algo sacrossanto e consentido. Contudo, não é bem assim: por toda parte, os contrafatos abundam, as incertezas aumentam, as fraturas crescem e ameaçam levar o sistema à ruína.

Sobre as métricas, não apenas reconhecemos seus enormes serviços ao discretizar e mensurar as coisas, como também seu papel de comparar os indivíduos e os conjuntos, além de operar as grandezas e manejar as escalas. As métricas incidem ainda sobre a qualidade, vez que a qualidade sai da quantidade e depende da escala, podendo sua densidade diminuir e ficar mais rala, ou aumentar e ficar mais densa: questão de massa crítica - como se diz. Todavia, se a qualidade não for buscada desde a saída e o ponto de partida, nas bases de dados e nos indexadores, jamais será achada nas fórmulas compostas e no ponto de chegada.

Sobre as alternativas e as saídas, elas são de várias ordens e delineiam vários caminhos, algumas pontuais e negativas, envolvendo ações defensivas e boicotes, outras de maior amplitude e positivas, como a criação de filtros de qualidade e a reforma do sistema de avaliação pelos pares por dentro. 
Quanto à primeira via, um excelente exemplo da atitude defensiva é o já citado Slow Science, criado em 2010 por Jonas Obleser, e braço do Slow Food, com o propósito de insurgir-se contra o tempo acelerado dos negócios em favor do tempo lento da ciência, justamente o ritmo requerido para ela poder digerir as coisas e "fazer seu trabalho" (Slow Science Academy, 2010). Três exemplos excelentes dos boicotes são o movimento patrocinado por um seleto grupo de universidades americanas (Harvard, Stanford, Duke etc.) contra o grupo Elsevier, secundado pelas Associações Americana e Europeia de Economia, bem como pelo matemático Tymothy Gowers, autor do manifesto "O custo do conhecimento" ("The cost of knowledge"), vindo a lume em janeiro de $2012-\mathrm{e}$ todos pelas mesmas razões, a saber, preços escorchantes das revistas das editoras, tendo as Associações criado as suas próprias.

Quanto à segunda via, e a começar pelos filtros, visando a instauração de um post-publicationn peer review, o exemplo é o F1000Research, ${ }^{4} \mathrm{em}$ alusão à época em que foi criado (2000), quando tinha mil leitores-pareceristas, e hoje com mais de dez mil cobrindo inúmeras áreas do conhecimento, tendo atingindo em 2011 a impressionante cifra de cem mil artigos ranqueados e comentados. E o que é da maior importância: sem o automatismo dos algoritmos que avaliam e ranqueiam sem ninguém ler. Menos desestabilizadoras são aquelas tentativas de reformar o sistema de revisão pelos pares por dentro. Duas são as direções. (1) Introduzir modificações em seu interior, com vistas a seu aperfeiçoamento, mantendo o instituto do anonimato (parecer cego). Assim, Science e outras revistas de primeira linha procedem à seleção de seus artigos combinando três processos: (a) escrutínio prévio pelos membros do comitê editorial; (b) avaliação feita por referees externos; (c) decisão final pelo Comitê. (2) Implantação de um sistema misto ou híbrido, sem romper inteiramente com o sistema de revisão pelos pares, podendo simplesmente eliminar um dos seus institutos (variante 1) ou acrescentar um novo expediente (variante 2). Assim, na primeira variante, trata-se de combinar a revisão cega pelos pares com o sistema de revisão aberto (quebra do anonimato), como vem fazendo Nature desde 2006, segundo consta. Na segunda variante, em que se enquadra a PLoS One, editada pela Public Library of Science desde 2006 e voltada para a medicina e a biologia, procura-se combinar o livre acesso aos artigos (on line), o sistema de revisão por pares, o direito à replica ou à resposta e o feedback da comunidade de leitores, abrindo a revista para ulteriores debates e comentários.

Tudo isso mostra que nessas matérias, terreno da ação e da contingência, não se está diante de uma fatalidade ou de um destino cego, como nas leis da natureza, mas a realidades abertas, históricas e reversíveis, ainda que pesadamente coercitivas e determinantes. É nesse quadro que se inscreve o problema das métricas e das distorções. Elas são reais, mas não fatais, e os remédios para os males, elas que não têm culpa de nada, têm de ser procurados fora delas, nas instâncias em que elas são usadas como ferramentas, bem como nos valores e 
padrões morais dos usuários das medidas e das ferramentas, ou seja, cientistas, administradores e staffs de governos.

Na instância do julgamento e da interpretação, alma mater dos júris e dos comitês, servindo elas mesmas de índice e parâmetro, municiadas, para além dos números, pelas informações geradas pelas visitas, reuniões presenciais, relatórios circunstanciados e séries históricas - este é o primeiro desafio. Na ética republicana, na esteira da ética das virtudes, e refundada para religar o éthos da ciência fraturado pelo taylorismo acadêmico: trata-se de uma alternativa à ética utilitarista, ante a necessidade de contrapor ao agonismo da competição que leva ao tudo ou nada do "publique ou pereça" o deleite da cooperação e da contemplação da obra que se pereniza e sobrevive ao indivíduo - é o segundo desafio.

Para terminar, a contrapelo da corrida ensandecida para chegar primeiro, citaremos Wittgenstein $(2000$, p.36r): "na corrida da filosofia, vence quem consegue correr mais devagar. Ou quem chega por último".

\section{Notas}

1 O campo semântico da taylorização de fato é mais extenso e outros aspectos serão considerados ao longo do artigo. Trata-se de pensar uma espécie de invasão da esfera acadêmica por certas práticas e procedimentos advindos da economia, imperando o pragmatismo, a óptica da quantidade e a busca da eficiência. Em sua obra famosa, Taylor reduziu a racionalidade econômica ao esquema da planilha baseada no tempo ("time-based Schedule" - devemos essa expressão a Hugh Lacey), que ele chamou de "princípio da administração científica", tendo como fim o aumento da produtividade do trabalho e, por extensão, da riqueza, e que poderemos traduzir livremente por meta/escala das tarefas e produtos em unidades de tempo, podendo a atividade ser medida tanto pelo tempo despendido quanto pelo produto ou seu resultado. Porém, a expressão "ratio taylorista" que a acompanha e que aparecerá mais insistentemente no final do artigo é criação nossa e foi inspirada em Parsons, que fala em "racionalidade cognitiva", empregando-a para pensar problemas parecidos. Antes de Taylor e Parsons, os jesuítas já falavam da ratio studiorum e a faziam o núcleo duro do seu sistema de ensino, extrapolando a matemática. Transportada para a área acadêmica no ambiente contemporâneo, indo além dos jesuítas, de Parsons e do próprio Taylor, a ratio taylorista integra à ratio matemática da economia, com métricas e cifras para tudo, a ratio normativa do direito, levando à exigência dos relatórios (accounts) e à estandardização dos procedimentos. Neste quadro entram os rankings, os indexadores, os editais, as prestações de contas etc.

2 Segundo os estudiosos, embora muito citada e havendo mesmo quem pretenda que ela estivesse afixada na parede de seu escritório no Instituto de Estudos Avançados de Princeton - as outras variantes falam que ela estava escrita em um quadro-negro -, a frase não é de Einstein, mas do médico britânico Sir George Pickering, que o cientista tinha citado, endossando-o (Garfield, 2010, p.56). Além de Pickering, há outros candidatos a titulares da frase, ainda que sem conexão com Einstein, como o sociólogo americano William Bruce Cameron.

$3 \mathrm{O}$ artigo traz na primeira página a foto do campeão de Wimbledon de 2001, Goran 
Ivanisevic, classificado $125^{\text {0 }}$ no início da competição, justificando a pergunta: "o que uma classificação realmente faz?”.

4 Sediada em Londres, a Faculty 1000 foi fundada por Vitek Tracz, a contrapelo do sistema de revisão pelos pares e dos índices de impacto, considerados "idiotas" por ele, preocupado em achar outras rotas para a avaliação e a comunicação dos artigos acadêmicos. Sobre Vitel Tracz, ver Rabensadrana (2013).

\section{Referências}

BUSH, V. Science: the endless frontier. Washington: Government Print Office, 1945.

CASTELFRANCHI, Y. As serpentes e o bastão: tecnociência, neoliberalismo e inexorabilidade. 2008. Tese (Doutorado em Sociologia) - Instituto de Filosofia e Ciências Humanas, Universidade Estadual de Campinas. Campinas, 2008.

COASE, N. R. H. The market for goods and the market for ideas. American Economic Review, v.64, n.2, p.384-91, maio 1974.

DUGA, J.; STUDT, T. Global R\&D report 2008. RéD Magazine, p.G3-G18, set. 2007.

GARFIELD, C. A. Peak performers: the new heroes of American business. New York: William Morrow, 1986.

HAZELKORN, E. Rankings and the battle for world class excellence: institutional strategies and policy choice. Paris: OECD, 2008. p.18. Disponível em: <http://www.oecd. org/site/eduimhe08/41203634.pdf>. Acesso em: 25 set. 2013.

HORTON, R. Genetically modified food: consternation, confusion and crack-up. $\mathrm{Me}$ dical Journal of Australia, v.172, n.4, 2000, p.148-9.

JINHA, A. Article 50 million: an estimate of the number of scholarly articles in existence. Learned Publishing, v.23, n.3, 2010, p.258-63.

LAWRENCE, P. Rank injustice: the misallocation of credit is endemic in science. $\mathrm{Na}$ ture, v.415, p.835-6, 2002.

. The politics of publication: authors, reviewers, and editors must act to protect the quality of science. Nature, v.422, p.259-61, 2003.

. Lost in publication: how measurement harms science. Ethics in Science and Environment Politics, v.8, 2008, p.9-11.

MABE, M. The growth and number of journals. Serials, v.16, n.2, p.191-7, 2003.

MERTON, R. K. Ensaios de sociologia da ciência [Organização e posfácio por Anne Marcovich e Terry Shinn]. São Paulo: Editora 34, 2013.

NATIONAL SCIENCE BOARD. Science and Engineering Indicators 2008, vol 1, NSB 08-01, $588 \mathrm{p}$.

NIETZSCHE, F. Sobre o futuro de nossos estabelecimentos de ensino. São Paulo: Loyola, 2003.

PARSONS, T.; PLATT, G. The American university. Cambridge: Harvard University Press, 1973. 
POWER, M. The audit society - rituals of verification. Oxford: Oxford University Press, 1997.

PRICE, D. de S. Science since Babylon. New Haven: Yale University Press, 1975.

RABENSADRANA, T. The seer of science publishing. Science, v.342, n.6154, p.66-7, out. 2013.

SLOW SCIENCE ACADEMY. The slow science manifesto, 2010. Disponível em: <slow-science.org>. Acesso em: 22 abr. 2014.

SPRAT, T. The history of the royal society of London, for the improving of natural knowledge. London: J. Martyn, 1667.

STRATERN, M. (Ed.) Audit cultures - Anthropological studies in accountability, ethics and the academy. London: Routledge, 2000.

TAYLOR, F. The principles of scientific management. New York; London: Harper, 1911.

TAYCHER, L. Books of the world, stand up and be counted! All 129,864,880 of you. Disponível em: <http://www.booksearch.blogspot.com>. Acesso em: 5 ago. 2010.

UNESCO. Number of researchers in developing countries is rising, according to Unesco Study, but women researchers still a minority. Press release de Media Services, 2009. Disponível em: <http://www.unesco.org/new/en/media-services/single->. Acesso em: 25 fev. 2014.

WATERS, L. Inimigos da esperança-publicar, perecer e o eclipse da erudição. São Paulo: Editora Unesp, 2006.

WITTGENSTEIN, L. MS 121. In: Wittgenstein's Nachlass. The Bergen Electronic Edition, Oxford, Oxford University Press, 2000.

ZIMAN, J. M. Il lavoro dello scienziato. Roma-Bari: Laterza, 1987.

Real science - What it is, and what it means. Cambridge: Cambridge University Press, 2004.

Agradecimentos - Ao serem consumados os trabalhos, trazendo os resultados a público nas mais variadas circunstâncias, contraímos dívidas de toda sorte com estudantes, colegas e amigos, e em especial com Yurij Castelfranchi, nosso habitual interlocutor nessas matérias e a quem devemos incontáveis favores, como boa parte das referências e dos levantamentos que foram apresentados neste artigo, provenientes de sua tese de doutorado.

RESUMO - O artigo pretende abordar os seguintes tópicos: (1) o taylorismo acadêmico, a big science e o impacto sobre o sistema de comunicação da ciência (livros, revistas, artigos etc.); (2) o sistema de revisão por pares, os indexadores, os fatores de impacto e os rankings; (3) a explosão das publicações, a auditagem de processos e as distorções sistêmicas; (4) a crítica à ratio taylorista e a busca de saídas. Para tanto, procuraremos combinar a análise de dados sociológico-estatísticos do sistema na atualidade e a abordagem histórica das tendências e dos legados.

PaLAVRAS-CHAVES: Produtivismo, Taylorismo acadêmico, Big science, Ratio taylorista, Métricas, Auditagem, Publicar ou morrer, Distorções sistêmicas, Filtros de qualidade. 
ABSTRACT - This paper aims at analyzing the following topics: (1) academic taylorism, big science and their impact on the science communication system (books, journals, papers etc.); (2) peer review system, database, impact factors and rankings; (3) boom of publications, auditing procedures and systemic distortions; (4) criticism to taylorist ratio and the search for solutions. To achieve this, we are going to mix analysis of current system's socio-statistics data and the historical approach of trends and legacies.

KEYWORDS: Productivism, Academic taylorism, Big science, Taylorist ratio, Metrics, Auditing procedures, Publish or perish, Systemic distortions, Quality filters.

Ivan Domingues é doutor em Filosofia pela Universidade de Paris 1, Sorbonne; professor titular do Departamento de Filosofia da FAFICH/UFMG; coordenador do Núcleo de Estudos do Pensamento Contemporâneo (NEPC)/UFMG; autor de vários livros e artigos no campo da filosofia contemporânea, filosofia das ciências sociais e filosofia da tecnologia. @ - domingues.ivan3@gmail.com

Recebido em 26.5.2014 e aceito em 31.7.2014.

${ }^{\text {I }}$ Faculdade de Filosofia e Ciências Humanas, Universidade Federal de Minas Gerais, Belo Horizonte/MG, Brasil. 